\title{
Aproximación tecnomorfológica a los vasitos chatos de Doncellas (Puna Septentrional argentina) a través de técnicas arqueométricas
}

\author{
Martina Inés PÉREZ \\ Facultad de Filosofía y Letras, Universidad de Buenos Aires (Argentina) \\ martinainesperez@hotmail.com
}

Recibido: 7 de febrero de 2012

Aceptado: 18 de septiembre de 2013

\begin{abstract}
RESUMEN
El artículo presenta los resultados de diferentes análisis arqueométricos realizados a los vasitos chatos de Doncellas (Puna Septentrional argentina). Por un lado se recurrió a la técnica radiográfica con el objetivo de identificar la estructura interna no visible en condiciones normales -orientación, tamaño, cantidad y distribución de las partículas y vacíos- y por el otro se realizaron una serie de cortes delgados para la determinación petrográfica de los recipientes. A partir del uso de estas técnicas se tratan aquí las diferentes elecciones de los alfareros a la hora de dar forma a estos objetos, como el empleo de moldes, rollos o placas. Considerando que el conocimiento de los procesos tecnológicos en sí mismos, y no meramente sus efectos materiales, es el que nos permite discutir aspectos sociales del pasado, se plantean una serie de hipótesis que exceden el análisis exclusivo de los objetos materiales.
\end{abstract}

Palabras clave: Doncellas, vasitos chatos, morfología, técnicas arqueométricas.

\section{A Tecnomorphological Approach to Vasitos Chatos from Doncellas (Northern Puna, Argentina) through Archaeometric Techniques}

\begin{abstract}
This paper presents the results of an archaeometric analysis of the vasitos chatos («short cups») from Doncellas (Argentine Northern Puna). On the one hand radiographic technique was used in order to identify the internal structure not visible in normal conditions -orientation, size, quantity and distribution of the particles and empty- and on the other hand a series of thin sections were performed for petrographic determination of the containers. Effective use of these techniques is discussed here in terms of the different choices of potters at the time of shaping these objects, such as the use of molds, coiling or plaques. As knowledge of technological processes in themselves, and not merely their material effects, is what allows us to discuss social aspects of the past, the paper raises a number of hypotheses beyond the exclusive analysis of material objects.
\end{abstract}

Key words: Doncellas, vasitos chatos, morphology, archaeometric techniques.

Sumario: 1. Introducción. 2. Caracterización de la cultura puneña: el caso Doncellas. 3. Principios básicos de la técnica radiográfica y su aplicación al estudio cerámico. 4. Análisis tecnomorfológico. 5. Los vasitos chatos. 6. Resultados de los estudios arqueométricos. 7. Discusión y conclusiones. 8. Referencias bibliográficas.

\section{Introducción}

Desde sus inicios, y entre numerosos objetivos, la arqueología americana ha mostrado interés por el conocimiento de las técnicas de modelado o de construcción utilizadas por los alfareros prehispánicos. Desde esa óptica los esfuerzos fueron dirigidos a identificar tanto las técnicas como las distintas etapas de manufactura que permitieron la obtención de los recipientes cerámicos. Estos estudios han sido desarrollados por arqueólogos de todo el mundo, posibilitando hoy en día la determinación de algunos patrones referentes a las técnicas constructivas que están íntimamente relacionados 
con cuestiones geográficas. Estos patrones obedecen a pautas o modelos utilizados por los artesanos que están vinculados ya sea al modus operandi (o manejo tecnológico) que guía la cadena de manufactura o a la utilización de herramientas específicas que permiten determinados productos finales.

En este sentido existen algunas diferencias, ampliamente divulgadas, que distinguen, por ejemplo, a la alfarería arqueológica del Viejo Mundo con la alfarería prehispánica del continente americano. Sin lugar a dudas la más destacada de estas diferencias, y profundamente contrastadas a través del registro arqueológico, es la utilización y extensa difusión del torno en la alfarería del Viejo Mundo como instrumento tecnológico que permitió la elaboración de piezas en serie. Básicamente se trata de un platillo circular sobre el cual se coloca la masa arcillosa a fin de trabajarla mientras la «mesa soporte» gira sobre un eje. Esta herramienta aparece en el Próximo Oriente ya en el IV milenio a.C., mientras que en Occidente fue introducido por los pueblos colonizadores del Mediterráneo al principio del I milenio a.C.

Del mismo modo, otro aspecto de la cadena operativa que marca una diferencia significativa en lo que respecta a la alfarería de una y otra parte del globo, es la utilización de técnicas de cocción que permitieron el vidriado en la cerámica de muchas zonas del Viejo Mundo. Ya en el IV milenio a.C. se registran en el Próximo Oriente las técnicas del esmalte, que evolucionan hasta influir en los productos clásicos de Grecia y Roma. Los esmaltes o vidriados consisten en barnices a base de plomo que funde a baja temperatura, muy usados en las terracotas asirio-babilónicas. También se utilizan para el vidriado productos como bórax o feldespato, que funden a alta temperatura, mientras que los esmaltes alcalinos son los más usados tanto en Egipto como en Siria y Persia.

Así como coexisten estas diferencias o patrones de manufactura a una escala intercontinental también es posible distinguir algunos patrones que se dan ya sea a nivel regional y, por qué no, en una escala micro. En este sentido algunos autores (Rice 1987; Rye 1981) argumentan que determinadas técnicas de modelado son características o «propias» de una zona geográfica o que obedecen ciertos sistemas de producción.

Ejemplo de ello, es la técnica de moldes que ha sido comúnmente aceptada como propia de un sistema especializado de producción ya que los mismos permiten una producción a gran escala de recipientes idénticos. Para esta técnica se prepara una sección de arcilla que luego será depositada en un molde, pudiendo ser este último de madera, de cerámica o cestas preparadas para tal fin. Con los moldes se puede fabricar todo el objeto o partes del mismo, siendo generalmente la base la que se confecciona de esta manera (Rice 1987). Sin embargo, algunos autores consideran que el empleo de moldes no solo se puede esperar en aquellas sociedades centralizadas o asociadas a imperios o estados del tipo Inca, Moche o Chimú en Sudamérica sino que también ha sido una técnica utilizada en sociedades sin estado, carentes de un sistema especializado de producción artesanal.

Otro ejemplo es la técnica de placas cuya utilización ha sido raras veces reportada por los arqueólogos para los alfareros prehispánicos del territorio argentino, no así para los alfareros de otras partes de América como México (Cristiani 2009), Bolivia (keros de cerámica Tiwanaku), etc. Esta técnica permite la confección de recipientes 
rectos, salvo algunas excepciones, o aquellos que por su gran tamaño deben realizarse en más de una etapa y se caracterizan por la regularidad de sus formas y dimensiones (Orton et al. 1997; Rice 1987).

A partir de lo expuesto y de la observación visual realizada a los vasitos chatos pertenecientes a la Colección Doncellas surge la inquietud de investigar en lo que refiere a sus técnicas constructivas, dado que las características observadas a simple vista nos plantean la posibilidad de que los mismos se hayan confeccionado mediante el empleo de moldes o la técnica de placas, hasta el momento no revelada en la literatura regional. Para cumplir con este objetivo se hace uso de dos diferentes técnicas arqueométricas, las cuales nos permiten obtener datos medibles y replicables. Por un lado se recurre a los ensayos radiográficos y por el otro al análisis de cortes delgados, utilizando para ello técnicas petrográficas, desde la perspectiva que vincula a las técnicas productivas con acciones socializadas en las que se conjugan los objetos con el material, la acción y la cognición (Lemonier 1986).

\section{Caracterización de la cultura puneña: el caso Doncellas}

Según Bennett et al. (1948), la arqueología del sector Boreal de la puna, no más allá de los $23^{\circ} 30^{\prime}$ (sector del altiplano que corresponde a la provincia argentina de Jujuy), se caracteriza por los entierros en grutas, las llamadas chullpas ${ }^{1}$ y el Puna complex que se encuentra íntimamente relacionado con la funcionalidad agrícola y ganadera. Este complejo ergológico puede definirse por la presencia de artefactos característicos, siendo los más típicos los de madera como cuchillones, horquetas, torteros, puntas de flechas, arcos, cucharas, tabletas de rapé, tubos para rapé, husos, instrumentos de telar, azadas, peines, agujas, palos plantadores, vasos, etc.

Entre los instrumentos de hueso destacan espátulas, tubos y cucharas, y son recurrentes las calabazas con o sin decoración. Con respecto al cuero, son frecuentes las ojotas y bolsas simples y es típica la cestería con la técnica de espiral. Si bien el metal no es muy común se conocen campanas, cinceles, pinzas, discos, placas y cuchillos. Cuando hace referencia a la cerámica, mencionan que la misma posee influencias incaicas y que no presenta características distintivas a excepción de algunas piezas exclusivas como por ejemplo los vasitos chatos. Este mismo autor sostiene que la arquitectura no se diferencia de la registrada en otras regiones aunque en dos yacimientos se encontraron menhires, algo poco usual para esta zona geográfica (Pucara de Rinconada ${ }^{2}$ y Doncellas).

El área arqueológica de Doncellas está constituida por una serie de sitios que incluyen desde estructuras habitacionales hasta zonas de cultivo, sepulcros y estruc-

\footnotetext{
1 Son construcciones funerarias rectangulares de dos a cuatro metros de frente, con una pared frontal y dos que se apoyan sobre las paredes de los farallones que se diferencian de las conocidas chullpas del territorio boliviano. Las paredes están revocadas y posiblemente hayan estado techadas con vigas de madera empotradas en la roca y paja. En ellas se encontraron inhumaciones de uno o más individuos y Ottonello (1973) llegó a contabilizar hasta 96 construcciones de este tipo.

2 Asentamiento de tipo conglomerado con defensa (Madrazo y Ottonello 1966) ubicado al suroeste de la laguna de Pozuelos en la puna jujeña.
} 


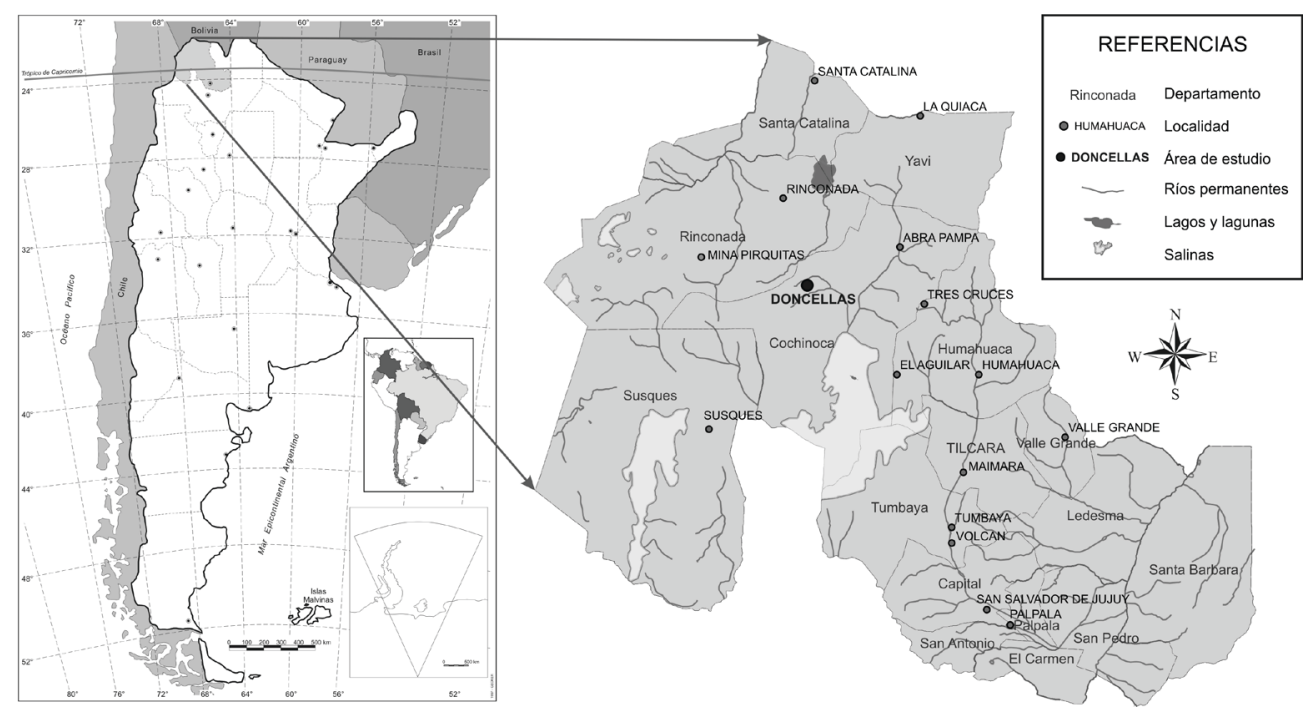

Figura 1: Ubicación geográfica de Doncellas.

turas que posiblemente estuvieron relacionadas a prácticas rituales. El sector del poblado abarca unas 2,5 ha de extensión, posee muros de delimitación de un metro y medio y está dividido por el cauce de una torrentera central. Se encuentra protegido por acantilados donde se hallaron recintos de planta circular, mientras que las construcciones centrales se dividen en habitaciones y grandes recintos de planta rectangular que se nivelan en terrazas sobre el declive de un terreno pedregoso (Ottonello 1973). En dirección norte llama la atención una estructura de piedra escalonada a la que se le ha asignado una funcionalidad religiosa (Alfaro 1988).

Con respecto a los enterramientos, Alfaro (1988) distingue varios tipos a los que denomina casas-tumbas (chullpas, sensu Ottonello 1973) que son construcciones adosadas a los farallones; grutas tapiadas, donde se aprovechan las cavidades naturales de los farallones; sepulcros de planta semicircular y sepulcros de planta circular o redonda. Todo este complejo arqueológico se encuentra ubicado a unos $3.500 \mathrm{msnm}$, en el borde oriental de la Puna Norte (departamento de Cochinoca, provincia de Jujuy, Argentina) en el tramo de la cuenca inferior de un curso afluente del río RachaiteDoncellas (Figura 1).

Las fechas de radiocarbono que se han obtenido hasta el momento (Alfaro 1988; Pérez de Micou 1996, 2009) permiten postular un largo periodo de ocupación que abarca los períodos Arcaico, Tardío, Incaico e incluso post-hispánico. Gran parte del material ergológico de Doncellas se enmarca dentro de lo que se ha denominado Puna complex (Bennett et al. 1948) o Complejo de la Puna (Krapovickas 1958-59), aunque se distinguen también componentes de filiación Tiwanaku (Alfaro 1988; Lafón 1965), Chicha (Ávila 2008; Pérez 2012) e Inca (Alfaro 1988; Gentile 2003; Lafón 1965; Ottonello 1973). 


\section{Principios básicos de la técnica radiográfica y su aplicación al estudio cerámico}

Una radiografía es una imagen registrada en una placa o película fotográfica. La imagen se obtiene al exponer dicha placa o película a una fuente de radiación de alta energía, comúnmente rayos $\mathrm{X}$ o radiación gamma procedente de isótopos radiactivos (Iridio 192, Cobalto 60, Cesio 137, etc.). De acuerdo a la densidad y grosor de los materiales que componen el objeto, estos absorberán más o menos rayos X, permitiendo transferir hacia la placa fotográfica una cantidad de fotones (rayos X) que se relaciona directamente con la densidad y grosor del objeto registrado. De esta manera en la placa resultante las partes más densas y de mayor grosor se manifestarán claras (debido a que son las zonas de mayor absorción) mientras que las partes menos densas del objeto y de menor grosor se presentarán oscuras por ser las que absorben menor cantidad de fotones, del mismo modo si los rayos atraviesan estructuras con aire se formará una imagen de color negro ${ }^{3}$.

En el caso de los estudios de materiales cerámicos arqueológicos la técnica radiografía ha sido utilizada con el fin de identificar las técnicas de manufactura cuando las mismas no pueden ser observadas a ojo desnudo (Carr 1993; Rye 1981). Por otro lado, se ha utilizado esta técnica con el objetivo de identificar la estructura interna no visible en condiciones normales - orientación, tamaño, cantidad y distribución de las partículas y vacíos- de los objetos (Berg 2008; Braun 1982; Carr 1993; Rye 1981; entre otros.) En Argentina el uso de esta técnica es relativamente reciente aunque los resultados alcanzados son muy fructíferos (De La Fuente et al. 2008; López 2001, 2008; López y Caramés 2000; López et al. 2010; Schuster 2010).

Con respecto a las ventajas que nos ofrece esta técnica en los análisis de los materiales cerámicos es importante destacar que la misma no es destructiva por lo que puede ser utilizado el objeto completo, y dada la flexibilidad que ofrece la placa fotográfica la misma se puede acomodar a la forma del objeto permitiendo tomar la imagen de una sola pared colocando la placa en el interior de las vasijas; sin embargo es importante mencionar que el uso de esta técnica es incompatible con posteriores estudios de datación por termoluminiscencia (Cristiani 2009; Orton et al. 1997). Por otro lado los costes de estos estudios no son demasiados altos y los resultados se pueden obtener en un corto tiempo, existiendo la posibilidad actual de adquirir los mismos en formatos digitales.

Cabe destacar que para la obtención de datos concretos resulta indispensable el diálogo continuo entre el arqueólogo y el personal técnico que realiza los ensayos.

\footnotetext{
3 Si bien este tipo de tecnología ha sido usada tradicionalmente en estudios de medicina, su aplicación en el campo de la industria ha demostrado ser altamente eficaz desde hace ya varias décadas. Como tipo de ensayo no destructivo esta técnica permite la detección de defectos en materiales y soldaduras tales como grietas, poros, etc., y es utilizado para inspeccionar materiales en busca de discontinuidades macroscópicas y variaciones en su estructura interna. La longitud de onda de los rayos X puede ser modificada al aumentar o disminuir el voltaje del tubo de rayos X, por lo tanto si se disminuye la longitud de onda los mismos tendrán un tamaño más pequeño por lo que su capacidad de penetración será mayor. Diferentes aplicaciones en el campo de los materiales cerámicos sugieren que para estos ensayos se requieren energías que oscilan entre los $30 \mathrm{y}$ los $150 \mathrm{KV}$ debido a que la cerámica es un material grueso que requiere de la utilización de kilovoltios altos.
} 
En este sentido es vital informar qué tipo de información se está buscando para la aplicación de una técnica adecuada.

\section{Análisis tecnomorfológico}

Según Rye (1981) todos los procesos de formación tienen un efecto sobre la orientación de las partículas que conforman a los recipientes cerámicos, este efecto se debe a que todas las técnicas de formación tienen la suficiente fuerza para realinear a las partículas que están 'flotando' en el agua. Entre estas técnicas se menciona la manipulación repetitiva de la arcilla, la presión de las manos o herramientas utilizadas para el modelado y en el caso de la utilización de moldes, las propiedades de absorción de los mismos.

En general, los estudios sobre las técnicas de formación de un objeto cerámico se llevan a cabo mediante observación visual de las marcas superficiales. Sin embargo, desde hace ya tres décadas aproximadamente, se han difundido los análisis que implican técnicas arqueométricas las cuales ofrecen datos de índole cualitativa y cuantitativa medibles y replicables. Dentro de este tipo de estudios son muy utilizados los análisis petrográficos que permiten conocer no sólo la composición mineralógica y química de las pastas cerámicas sino también en la orientación de las inclusiones, utilizando para ello técnicas analíticas que provienen generalmente de la geología.

Al referirse a las técnicas constructivas Rye (1981) reconoce tres procesos distintivos: los primarios, a través de los cuales se le da la forma básica al objeto, los secundarios en el cual se definen los detalles de formación y por último las modificaciones superficiales que incluyen a todas aquellas técnicas que modifican la textura superficial y definen las características estilísticas de los objetos cerámicos.

Con respecto a las técnicas primarias, y como ya se mencionó en un principio, en América prehispánica no se conoce la utilización del torno para la producción de objetos cerámicos y las técnicas de modelado incluyen el ahuecamiento (pinching or hand holding), la formación por tiras planas de arcilla también conocida como técnica de placas (slab modeling), por rollos (coiling) o por moldes (molding) (Rice 1987; Rye 1981). La técnica de ahuecamiento consiste en sostener un bollo de arcilla en la mano, hacer un hueco en el centro con la otra mano y luego estirar la arcilla hacia arriba con los dedos, otorgándole forma a las paredes mientras se va rotando la masa. La técnica de rollos consiste en realizar rollos de arcilla e ir añadiéndolos uno encima del otro. Una vez llegado a la altura deseada las paredes se alisan, ya sea presionando con los dedos o por medio de alguna herramienta adecuada para tal fin. También se conoce la utilización de un solo rollo largo que se va enrollando en forma de espiral hasta alcanzar la altura deseada. La técnica de formación por tiras planas de arcilla o por placas se basa primariamente en realizarlas bien mediante el modelado o bien presionando un bloque de arcilla contra una superficie plana para posteriormente cortar la parte superior con alguna herramienta y luego unirlas unas con otras ocultando las uniones mediante presión. Esta técnica ha sido registrada para la confección de objetos rectos, aunque existen excepciones como en el caso de recipientes de grandes dimensiones (Orton et al. 1997; Rice 1987). Por último la fabricación a partir del 
moldeado se realiza utilizando hormas o moldes sobre los cuales se coloca la arcilla que toma la forma de los mismos. Estos moldes por lo general son de cerámica, pero también se han registrado en otros materiales como canastos de fibra, piedra, madera, etc. Cuando la arcilla toma la forma deseada se eliminan los sobrantes con algún instrumento apropiado. Esta última técnica permite también la inclusión de alto o bajo relieves que se imprimen en el objeto cerámico y a su vez proporciona objetos altamente estandarizados.

\section{Los vasitos chatos}

La terminología utilizada para denominar a estos recipientes es variada, y así se les conoce con el nombre de vasitos puneños, pequeños vasos chatos (Casanova 1938, 1943), vasitos chatos (Krapovickas 1958-59) o vasitos hilanderos según Gatto (1943) porque algunos ejemplares poseen un hueco en su base cuya función podría ser, según este último autor, la de sostener el huso al hilar.

De acuerdo a Krapovickas, los mismos son exclusivos de la puna, con excepción de algunos registrados en la Quebrada de Humahuaca, donde siempre se presentan en abundancia. Este autor, contabiliza 34 de las 86 piezas analizadas para el caso de Doncellas, aunque para esta investigación se contabilizaron 69 vasos procedentes del sector de tumbas, ubicados en la Colección Doncellas del Museo Etnográfico Juan Bautista Ambrosetti de la Ciudad Autónoma de Buenos Aires y del Instituto Interdisciplinario de Tilcara (Jujuy), ambos dependientes de la Facultad de Filosofía y Letras de la Universidad de Buenos Aires. Por otro lado del material cerámico procedente del área del poblado, se contabilizaron 22 de estos recipientes entre fragmentos y piezas completas los cuales hoy pertenecen a la colección Doncellas depositada en el Instituto Nacional de Antropología y Pensamiento Latinoamericano de la Ciudad Autónoma de Buenos Aires.

En cuanto a su morfología los mismos se presentan como pequeños vasos cilíndricos, cónicos o troncocónicos, confeccionados con pastas amarronadas, cuya base es amplia ( $7 \mathrm{~cm}$ en promedio de diámetro) y plana (Figura 2). Poseen una altura promedio de $5 \mathrm{~cm}$ siendo, en esta muestra analizada, los más bajos de $3,9 \mathrm{~cm}$ y los más altos de $5,8 \mathrm{~cm}$. Su borde es recto con una terminación redondeada o, en algunos casos, biselada. La superficie de estos objetos generalmente es muy regular, sobre todo en sus paredes que se presentan planas (apenas cóncavas en algunas excepciones) con un grosor uniforme que se mantiene desde el inicio de las mismas hasta el mismo borde ( $6 \mathrm{~mm}$ en promedio) y su base se presenta, por lo general, ensanchada.

A simple vista, en la mayoría de estos recipientes, no es posible identificar en las paredes las uniones características de la técnica de rollos ni marcas de ahuecamiento como segunda opción de modelado (Figura 3). Sólo es detectable el ensamble de las paredes con las bases (Figura 4) que es donde estos recipientes toman un grosor mayor y por donde generalmente se fracturan, seguramente como consecuencia de esta unión. Dadas las características detectadas y mencionadas anteriormente nos permitimos pensar en la probable utilización de la técnica de modelado mediante placas o en la probable utilización de moldes para la confección de estos recipientes particulares. 


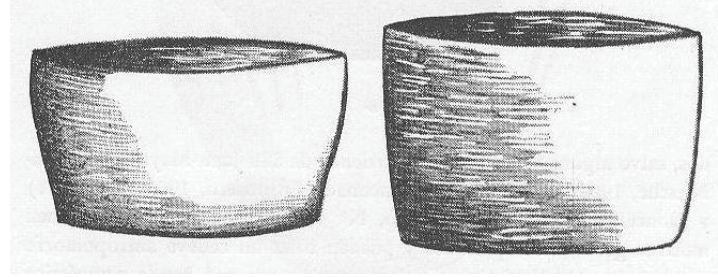

Figura 2: Vasitos chatos (modificado de Krapovickas 1958-59: 57).
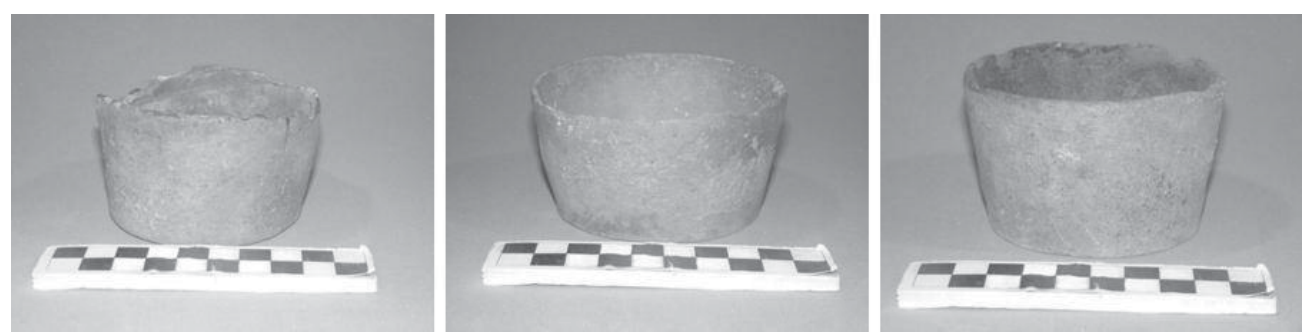

Figura 3: Vasitos chatos pertenecientes a la Colección Doncellas del Museo Etnográfico «Juan B. Ambrosetti» (FFyL, UBA) N 44-1105, 44-1106 y 43-1089.

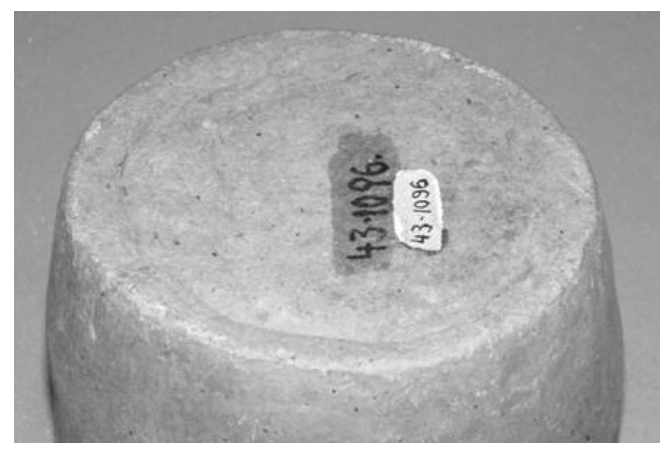

Figura 4: Detalle de la unión de las paredes con la base. Colección Doncellas del Museo Etnográfico «Juan B. Ambrosetti» (FFyL, UBA) N 43-1096.

Figura 5: Vasito chato con orificio en su interior. Colección Doncellas del Museo Etnográfico «Juan B. Ambrosetti» (FFyL, UBA) $\mathrm{N}^{\circ} 44-1106$.

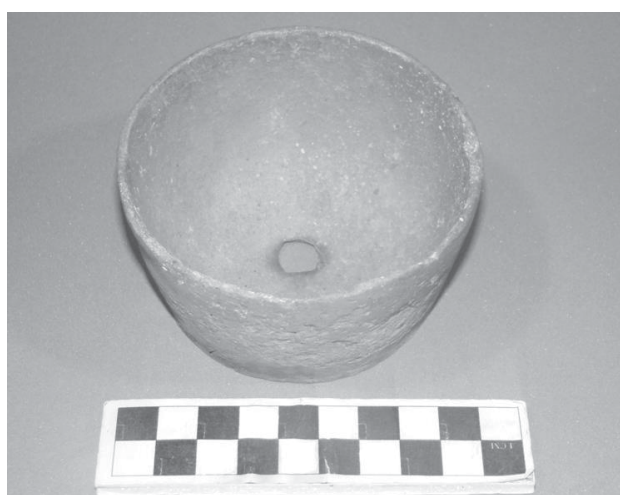

Si nos remitimos a su forma, los mismos podrían estar vinculados a una función alimenticia relacionada con el servicio de alguna sustancia liquida (agua, chicha, etc.). Si nos detenemos en que muchos de ellos tienen un agujero en el centro (Figura 5) se podría llegar a sostener la idea de Gatto (1943) que los vincula con la actividad textil. No debería tampoco descartarse la posibilidad de que esta recurrencia en buena parte de los ejemplares responda a costumbres asociadas con los ritos funerarios como es el caso de textiles y bozales realizados ex profeso para estos rituales (Pérez 
de Micou 2001), aventurando la hipótesis de que los agujeros que presentan estén relacionados con el acto de «matar» al objeto en algún tipo de ritual mortuorio (Krapovickas 1977).

Si bien Casanova (1938) advierte la presencia de alguna sustancia en estos vasos y anteriormente Rosen (1916) los encuentra con ocre en su interior, en la muestra analizada sólo un bajo porcentaje (16\%) presenta macroscópicamente manchas de lípidos o adherencias no identificadas.

Como parte de esta misma investigación, y para llegar a resultados más concluyentes relacionados con la funcionalidad de estos vasos, se prevén realizar análisis de adherencias con cromatografía gaseosa los cuales aportaran datos acerca de las posibles sustancias de su interior.

\section{Resultados de los estudios arqueométricos}

\subsection{Técnica radiográfica}

Para la determinación de las técnicas de modelado se recurrió a los ensayos radiográficos utilizando un equipo Philips modelo MCN 165 perteneciente al grupo INEND de la CONEA (Ciudad Autónoma de Buenos Aires). El voltaje utilizado para las tomas estuvo en el rango de los 40 a los $42 \mathrm{KV}$ con un foco de $0,4 \mathrm{~mm}$, a una distancia de $70 \mathrm{~cm}$ y con un tiempo promedio de 1 minuto. Para las placas fotográficas se utilizó una película tipo AA400 y también se digitalizaron las imágenes.

Por otro lado se recurrió a la toma de imágenes en tiempo real utilizando un sistema radiográfico digital. Este sistema está compuesto por un tubo de RX de potencial constante para uso industrial y un equipo intensificador de imágenes para la detección de los RX. La imagen digital es adquirida por un software específico para radiografía y procesada con la ayuda de filtros digitales (Tachia, comunicación personal 2010). Este tipo de imágenes, proporciona una excelente calidad de imagen visible en un formato digital, y permite identificar rápidamente defectos sutiles e indicaciones sin ambigüedad alguna. En las imágenes obtenidas a partir de estos ensayos, al contrario de lo que sucede en la radiografía común, las partes más densas y de mayor grosor se manifestarán oscuras mientras que las partes menos densas del objeto y de menor grosor se presentarán claras. Para este trabajo se tomaron una serie de radiografías a 7 vasitos chatos considerando el frente, el fondo y el perfil de los recipientes.

La bibliografía específica (Berg 2008; Rye 1981) señala que en general las inclusiones de la pasta cerámica se orientan perpendicularmente a la dirección de la presión que se ejerce al modelarla y esta orientación varía de acuerdo a la técnica empleada. Existen dos formas de observar este fenómeno en los recipientes cerámicos: con imágenes radiográficas o en cortes delgados utilizando técnicas propias de la geología para cuantificar la orientación de las inclusiones. Es importante destacar que, para observar correctamente esta orientación, los cortes delgados deben realizarse de manera vertical a la forma de los recipientes.

Cuando se trata de un objeto formado por rollos, en una sección delgada las inclusiones se observan orientadas al azar en un corte transversal vertical (o sea per- 


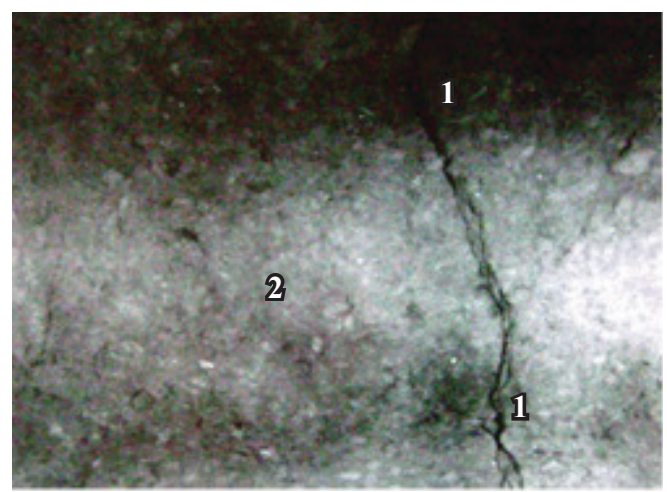

Figura 6: Imagen digital que permite observar las zonas de unión de un rollo (1) y el rollo propiamente dicho (2) (López et al. 2010).
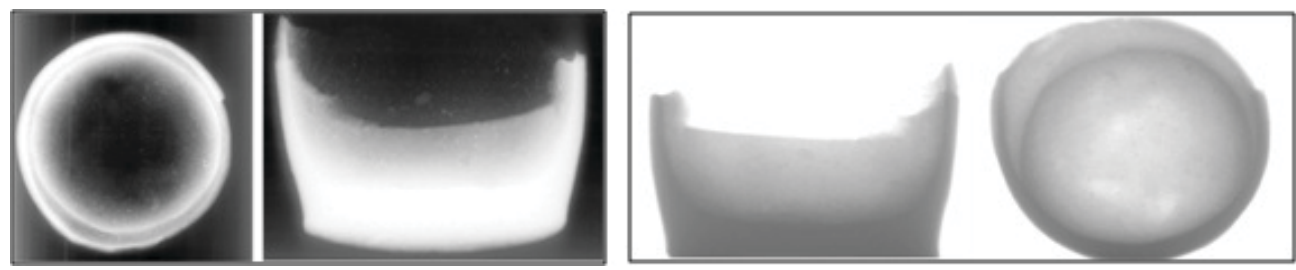

Figura 7: Imágenes radiográficas del objeto ${ }^{\circ} 21$ a (izquierda radiografías convencionales, derecha radiografías en tiempo real).

pendicular a la dirección de los rollos); en cambio, en la imagen radiográfica de la superficie, las inclusiones se observan orientadas paralelamente a lo largo del centro de cada rollo. En el caso de la técnica de ahuecamiento, en las secciones delgadas cortadas perpendiculares a la dirección del recipiente, las partículas pueden verse a veces orientadas de manera vertical por el jalado que las manos ejercen hacia arriba, mientras que en las radiografías se observan orientadas al azar. En el caso de la técnica de placas y de moldes las inclusiones se orientan paralelas a la superficie en las secciones delgadas, pero de manera aleatoria en las imágenes radiográficas (Rye 1981). Por otro lado, se menciona que algunos procesos de modelado pueden dejar vacíos característicos, a los cuales se les conoce como vacíos de unión ya que, como su nombre indica, se forman entre dos trozos de arcilla que han sido unidos entre sí, como sería el caso de los rollos (Figura 6), la unión entre las distintas partes o el agregado de algún accesorio como asas o soportes.

En nuestro caso, las imágenes radiográficas (Figuras 7 y 8), en especial las que toman el perfil de los objetos cerámicos, nos muestran claramente que para el modelado de los mismos no se ha hecho uso de la técnica de rollos, ya que no se observan los vacíos de unión especificados en líneas anteriores, motivo por el cual se puede descartar el uso de esta técnica para la confección de los vasitos.

Por otro lado, las imágenes radiográficas permiten observar que las paredes poseen grosores y densidades muy homogéneas y compactas, características que confirman las apreciaciones hechas a simple vista. Esta regularidad de las paredes se puede relacionar ya sea con la técnica de placas o con el moldeado. La posibilidad de la utilización de moldes podría descartarse debido a que las imágenes no evidencian las «costuras» propias de la utilización de moldes que resultan de la unión de las 

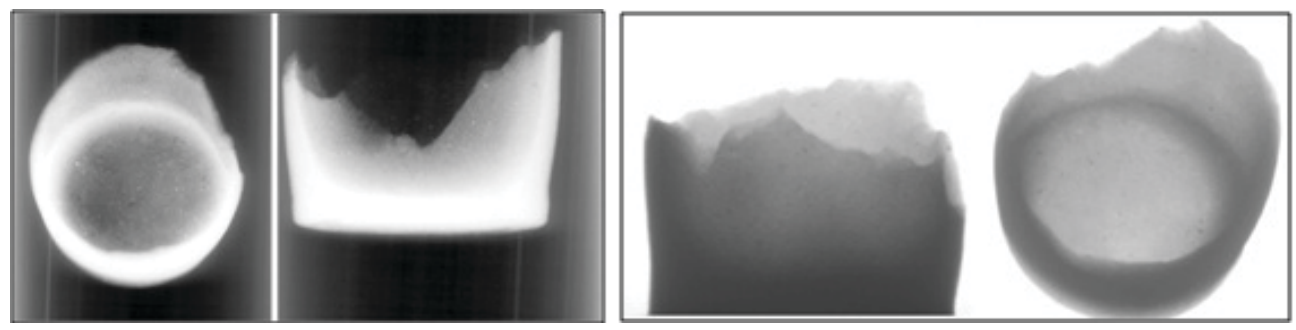

Figura 8: Imágenes radiográficas del objeto ${ }^{\circ} 451$ (izquierda radiografías convencionales, derecha radiografías en tiempo real).

distintas partes de las piezas. Además, en las radiografías es posible observar que la sección inferior de las paredes presenta un ensanchamiento donde éstas se unen con el fondo o base del recipiente, y a su vez esta base se presenta completamente plana, homogénea y compacta, lo que indicaría que se trata de una placa.

Otro dato relevante es que es muy frecuente encontrar las bases separadas del resto de los objetos, característica que refuerza la unión de las paredes con el resto del cuerpo de los vasos y por lo tanto la tendencia a que sea ese el sector donde se producen las fracturas.

Con respecto a la orientación de las inclusiones en las imágenes radiográficas (y utilizando un zoom) es posible observar que, en las paredes de los vasitos, las mismas se encuentran orientadas al azar (Figura 8), propiedad que se correlaciona con la utilización de la técnica de placas.

\subsection{Microscopía óptica de láminas delgadas}

Esta técnica posibilita el estudio petrográfico de las pastas cerámicas mediante un análisis cualitativo y semicuantitativo, utilizando para ello un microscopio de luz polarizada. Para este tipo de análisis se realizaron 4 cortes delgados provenientes de las muestras del INAPL y fueron tomados exclusivamente en fragmentos de vasos o en piezas que ya presentaran algún tipo de faltante o rotura. A su vez, y a fines comparativos, se realizaron 4 cortes delgados a fragmentos de cerámica no decorada proveniente del sector del poblado donde la misma representa un alto porcentaje (49\%, ver Pérez 2008 para más detalle) comparada con el resto de los grupos estilísticos hallados por Alfaro de Lanzone en la excavación del poblado.

Las variables consideradas en el análisis fueron el porcentaje de matriz y el porcentaje de poros a partir de la estimación semicuantitativa realizada con tablas de porcentajes tomadas de Folk y colaboradores (1970), y la naturaleza de las inclusiones cuya estimación, también semicuantitativa, se realizó en base a conteos por campos visuales de ocular.

Con el concepto de inclusión o desgrasante se hace referencia a aquellos agregados de la pasta (minerales, líticos, tiesto molido o materiales orgánicos) que pueden estar presentes en la arcilla por procesos naturales o intencionales por parte de los productores, y que permiten el modelado al disminuir las propiedades plásticas de la arcilla. Por otra parte, el término matriz se utiliza para definir los fondos de pasta cuyos componentes son las arcillas y las inclusiones muy finas incluidas naturalmente 


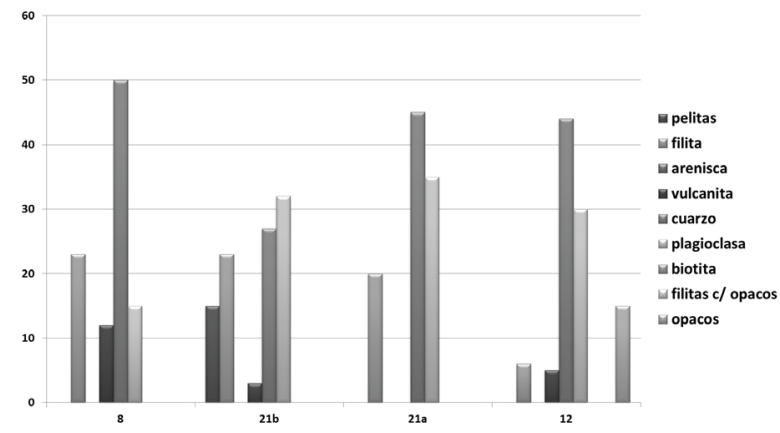

Figura 9: Petrografía de los vasitos chatos.

en estas (Cremonte 1996). Utilizando la escala de Wentworth (1922) para rocas sedimentarias, los tamaños menores a $0,04 \mathrm{~mm}$ corresponden a la matriz y los mayores a las inclusiones, separación que establece el límite entre arena muy fina y arcilla.

Por último, los poros son los pequeños espacios de aire o cavidades presentes en la pasta que pueden ser consecuencia de la cantidad o tipo de inclusiones, del modelado ineficiente que se le dio a la pasta o debido a la calcinación de ciertos materiales orgánicos, entre otras causas posibles.

Si bien los vasitos chatos se encuentra incluidos en la categoría de cerámica no decorada, en su momento se tomó la decisión de realizar un análisis petrográfico a este tipo de recipientes porque se observó que los mismos presentaban regularidades en lo que respecta a su morfología como por ejemplo el grosor de sus paredes, la altura, el diámetro de boca, el diámetro de base y en algunos casos el color de la pasta. Por otro lado en los mismos es posible observar una cuidadosa técnica constructiva, todo esto en su conjunto nos llevó a la determinación de aislarlos como subgrupo a los efectos de realizar análisis que permitieran indagar en su tecnología.

El análisis petrográfico comparativo realizado a las muestras de los vasitos chatos arrojó resultados que apartan a este conjunto del resto de la cerámica no decorada, presentando estos una mayor estandarización en sus componentes petrográficos, lo cual podría indicar una intencionalidad por parte de los alfareros a diferenciar con características particulares este tipo de recipientes.

Es notable como en los distintos cortes los componentes petrográficos de las muestras pertenecientes a los vasitos chatos se repiten tanto en tipo como en cantidades promedio, siendo el cuarzo el tipo de inclusión más abundante en todas las muestras con un porcentaje que abarca de un 27 a un 50\%. Le sigue la plagioclasa como mineral más representativo en las muestras con porcentajes que van del 15 al 34\%, y en tercer lugar las filitas que también repiten sus proporciones en tres de las cuatro muestras ( $20 \%$ promedio y $7 \%$ en la cuarta muestra). Como componente minoritario tres de las cuatro muestras presentan vulcanita y sólo una contiene minerales opacos (14\%) (Figura 9).

Al contrario, las muestras correspondientes a la cerámica no decorada no evidenciaron una estandarización tan evidente, el cuarzo es el único componente que se repite en el total de las muestras, aunque las cantidades de cada una de ellas son mucho menos homogéneas $(62,57,38$ y $27 \%)$. Tres de las muestras presentan areniscas, dos minerales opacos y solo una, la muestra 7, pelitas. La filita es el único componente 
Figura 10: Petrografía de la cerámica no decorada.

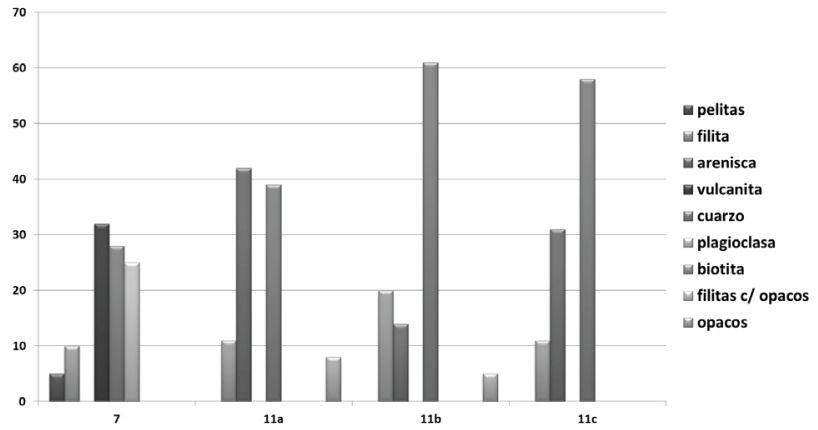

que se repite en porcentajes homogéneos en todas las muestras (promedio 20\%) (Figura 10).

Con respecto al tipo de pastas, si bien el porcentaje de matriz, inclusiones y porosidad tienen diferencias representativas en ambos tipos de muestras (Cuadro 1), los vasitos poseen en todos los casos una textura fina, lo cual está dado por el tamaño pequeño de todas sus inclusiones. Este hecho no se repite en el resto de cerámica no decorada que tienen una textura de mediano a mediano gruesa con tamaños más grandes de sus inclusiones. A su vez el color de las pastas es más uniforme en los primeros, siendo siempre variedades del 5 Y3 de la escala Munsell.

En lo que respecta a la orientación de las inclusiones, para observar las mismas en los cortes delgados (en una sección vertical) se utilizaron técnicas de conteo de la geología para aquellas inclusiones petrográficas que tuvieran más de $5 \mathrm{~mm}$ y cuya forma fuera tabular (más larga que ancha), aspecto que también se tomó con respecto a los poros. Se tomaron como variable los siguientes parámetros: (1) Orientadas: aquellas que se encontraran totalmente paralelas al borde del corte o con un ángulo menor a $25^{\circ}$. (2) Poco orientadas: los que tuvieran un ángulo entre $55^{\circ}$ y $25^{\circ}$. (3) No orientadas: aquellas que superaran $\operatorname{los} 55^{\circ} \mathrm{o}$ estuvieran totalmente perpendiculares al borde del corte.

En el Cuadro 2, se pueden observar los resultados obtenidos, considerando que la petrografía nos muestra un bajo porcentaje de inclusiones tabulares (aprox. el 16\%). Si bien en uno de los cortes las inclusiones no se orientan mayoritariamente paralelas a la superficie en los otro tres es notable como las mismas si presentan esa orientación

Cuadro 1: Porcentajes de matriz e inclusiones y color de las pastas según tablas de colores Munsell.

\begin{tabular}{|c|c|c|c|c|c|c|}
\hline \multirow[t]{2}{*}{ Muestra } & \multirow{2}{*}{$\begin{array}{c}\text { Grupo } \\
\text { tipológico }\end{array}$} & \multicolumn{2}{|r|}{ Matriz } & \multirow[t]{2}{*}{ Color } & \multirow{2}{*}{$\begin{array}{c}\text { Porosidad } \\
\%\end{array}$} & \multirow{2}{*}{$\begin{array}{c}\text { Inclusiones } \\
\%\end{array}$} \\
\hline & & $\%$ & Tipo/textura & & & \\
\hline 7 & No decorada & 65 & mediana & $10 \mathrm{R}(6 / 6)$ & 15 & 20 \\
\hline $11 \mathrm{a}$ & No decorada & 75 & mediana & 7.5Y R (6/3) & 15 & 10 \\
\hline $11 b$ & No decorada & 70 & mediana & 7.5Y R (5/3) & 15 & 15 \\
\hline $11 \mathrm{c}$ & No decorada & 85 & mediana & 7.5Y R (6/4) & 5 & 10 \\
\hline 12 & Vasito chato & 75 & fina & $5 Y 3(5 / 2)$ & 10 & 15 \\
\hline $21 b$ & Vasito chato & 55 & fina & $5 Y 3(6 / 2)$ & 20 & 25 \\
\hline $21 \mathrm{a}$ & Vasito chato & 65 & fina & $5 Y 3(7 / 6)$ & 10 & 25 \\
\hline 8 & Vasito chato & 75 & fina & $5 Y 3(4 / 1)$ & 10 & 15 \\
\hline
\end{tabular}




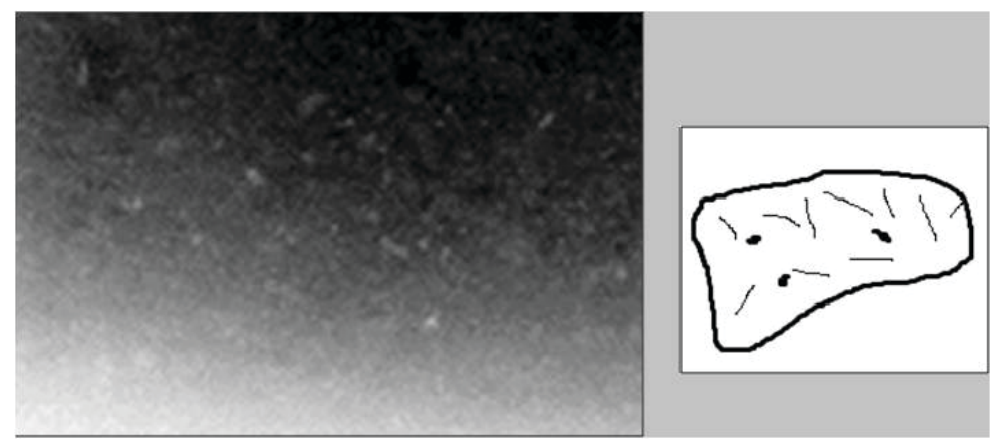

Figura 11: Vista de inclusiones en placa radiográfica.

Cuadro 2: Orientación de las inclusiones.

\begin{tabular}{lccccccc}
\hline & \multicolumn{3}{c}{ Inclusiones } & & \multicolumn{3}{c}{ Poros } \\
\cline { 2 - 3 } \cline { 7 - 8 } & Orientadas & $\begin{array}{c}\text { Poco } \\
\text { orientadas }\end{array}$ & $\begin{array}{c}\text { No } \\
\text { orientadas }\end{array}$ & Orientados & $\begin{array}{c}\text { Poco } \\
\text { orientados }\end{array}$ & $\begin{array}{c}\text { No } \\
\text { orientados }\end{array}$ \\
\hline Corte 12 & $37 \%$ & $26 \%$ & $37 \%$ & & $67 \%$ & $0 \%$ & $33 \%$ \\
Corte 8 & $69 \%$ & $19 \%$ & $12 \%$ & & $75 \%$ & $0 \%$ & $25 \%$ \\
Corte 21 a & $75 \%$ & $0 \%$ & $25 \%$ & & $33 \%$ & $67 \%$ & $0 \%$ \\
Corte 21 b & $64 \%$ & $36 \%$ & $0 \%$ & & $60 \%$ & $40 \%$ & $0 \%$ \\
\hline
\end{tabular}

(Figura 11). Con respecto a los poros, los resultados siguieron el mismo patrón de las inclusiones. Esto se corresponde, nuevamente con los parámetros de Rye (1981) propuestos para la técnica de placas.

\section{Discusión y conclusiones}

En lo que respecta a la interpretación formal de estos recipientes, López (2004 citado en Otero 2006) menciona que la regularidad que presentan los vasos chatos procedentes de la Quebrada de Humahuaca (provincia de Jujuy), podría estar asociada con el empleo de moldes para la confección de los mismos. Asimismo esta autora sugiere el empleo de los moldes para la formatización de un disco basal sobre el cual posteriormente se levantarían las paredes, aunque también plantea el uso de la técnica de ahuecamiento para este tipo de recipientes.

Por otro lado, Otero (2006) al analizar un cántaro Tilcara Negro sobre Rojo procedente del pucará de Tilcara (provincia de Jujuy), observa que su base de contorno muy regular, con paredes casi rectas y bastantes divergentes, presenta una similitud con los vasos chatos de la Quebrada de Humahuaca. La autora concluye que estas bases son el producto de la confección mediante el empleo de moldes ya que en las mismas se observa, a partir de un corte delgado, la costura propia de la unión de las distintas partes de la pieza como así también la distinta orientación de las inclusiones en la pasta de las diferentes partes. Mientras que la parte superior de la vasija, realizada mediante la técnica de rollos, presenta la orientación de las inclusiones dispuestas al azar, en la base las inclusiones se orientan en forma paralela al borde. 
Figura 12: Vista de inclusiones en corte petrográfico.

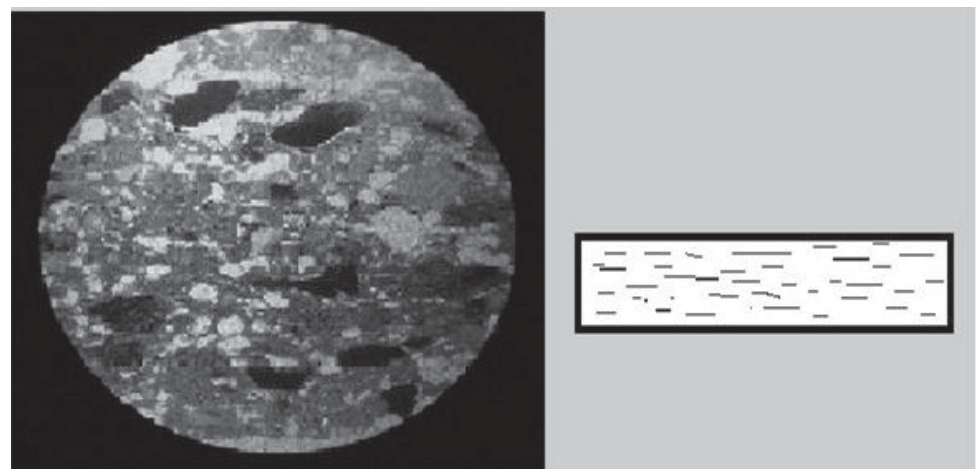

Esta misma autora realiza un análisis petrográfico a dos muestras pertenecientes a dos vasos chatos, encontrando en una de ellas una discontinuidad en la orientación de las inclusiones de la base y el resto del recipiente. En el cuerpo del vaso la orientación de las inclusiones se presenta al azar y en la base se orientan paralelas al borde. La autora concluye que para la manufactura de esta base, los alfareros optaron por el empleo de moldes y que no necesariamente este tipo de técnica se encuentra asociada a un sistema de producción especializado ni una gran escala de elaboración.

En el análisis de nuestra muestra descartamos el empleo de moldes ya que no se observan ni macroscópicamente ni en las imágenes radiográficas las costuras características y proponemos la utilización de placas para la confección de los vasos. Por otro lado es importante destacar que en los cortes petrográficos (Figura 12), la orientación de las inclusiones según Rye (1981) se presenta igual en aquellos recipientes realizados con moldes que en aquellos realizados por placas (paralelas al borde en corte vertical).

A partir de los análisis y ensayos realizados a los vasitos chatos de Doncellas fue posible determinar algunos aspectos que nos brindan información referente a las técnicas utilizadas por estos alfareros prehispánicos y a sus modos de hacer. Estamos convencidos de que el conocimiento de estos aspectos tecnológicos es la puerta de entrada a la hora de comprender otros aspectos de estas sociedades. Hacer una antropología de la tecnología es considerar a las técnicas en sí mismas y no meramente sus efectos materiales ya que éstas manifiestan aquellas elecciones tomadas por la sociedad dentro de un amplio universo de posibilidades (Lemonnier 1986).

Consideramos a la alfarería como una práctica más de estas sociedades puneñas y el hecho de que determinados objetos se realicen de determinadas maneras y no de otras nos está indicando que en la realización de esta práctica alfarera hay elecciones que superan las decisiones de los individuos que las realizan. Según Lemonnier (1986) las técnicas ponen en juego a los materiales, las secuencias de acción, las herramientas (incluyendo al cuerpo humano) y un conocimiento particular. Este último incluye el saber cómo hacer, las habilidades manuales, los procedimientos, pero también, un grupo de representaciones culturales sobre la «realidad».

La manufactura de los vasitos chatos demuestra que, dentro de un amplio universo de técnicas de modelado, los alfareros optaron por una tecnología que implica la acción encadenada de varias etapas. Desde el punto de vista de los comportamientos 


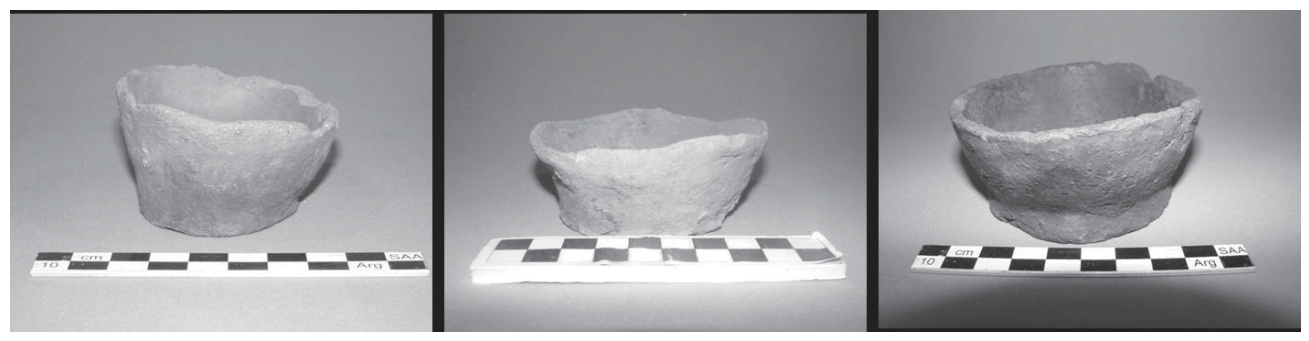

Figura 13: Ejemplos de vasitos chatos con defectos en el modelado. Colección Doncellas del Museo Etnográfico «Juan B. Ambrosetti» (FFyL, UBA) N 41-476, 43-1103 y 41-475.

humanos, el hecho de realizar estos recipientes, al menos la mayoría de los ejemplos de la muestra analizada, mediante el uso de placas requiere un amplio conocimiento de la técnica en la que primero se elabora la pasta, luego se definen las placas y posteriormente se ensamblan las diferentes partes. Entre los recipientes analizados, se han hallado algunos que presentan defectos en el modelado, lo cual nos permite inferir que la elaboración de esos vasitos requirió de un aprendizaje, seguramente generacional, que incluyó un proceso continuo de prueba y error (Figura 13). Es posible que los alfareros, en la búsqueda de un producto final que a la vista de la comunidad mantenga regularidades formales y métricas, hayan optado por esta técnica que si bien implicaba un paso más dentro de la cadena operativa, era la más adecuada para lograr el resultado final.

Volviendo a Lemonnier, este autor nos plantea la importancia de detectar aquellas discontinuidades en la cultura material (o variantes) ya que las elecciones técnicas de las sociedades están establecidas a través de criterios que no son materiales, y éstas siempre dejan rastros en su sistema de representaciones. Siguiendo este tipo de razonamiento se podría considerar a la técnica de placas como una discontinuidad en la manera de realizar recipientes cerámicos, ya que el resto del conjunto cerámico puneño se realiza ya sea por la técnica de rollos o por ahuecamiento. Como nos alerta este autor no deberíamos buscar para ello una explicación estrictamente materialista, sino indagar en argumentos relacionados con pautas culturales que rigen los comportamientos de las sociedades.

Hasta el momento no podemos determinar estrictamente el uso de estos recipientes, pero sí podemos inferir algunas cuestiones dentro del terreno de las hipótesis. Consideramos probable que estos vasitos estuvieran vinculados con algún tipo de actividad ritual, ya que es muy común encontrarlos asociados a los enterramientos en la puna y otras regiones del noroeste argentino. En este caso los mismos podrían estar relacionados con el consumo de chicha durante el ritual funerario o ser portadores de algún tipo de sustancia específica. Esto último podría estar relacionado con la amplia distribución que tienen en todo el noroeste argentino, no sólo este tipo de recipientes, sino también aquellas prácticas rituales asociadas a ellos.

Otra interpretación podría retomar aquellas posturas que vinculan el uso de estos vasos a la actividad del hilado, como ya se mencionó anteriormente. En este caso, y considerando que la actividad textil ocupó un lugar importante en la sociedad de 
Doncellas durante el período incaico (Alfaro 1988), no debemos desestimar el rol preponderante que denotaba dicha actividad dentro de estas sociedades.

Ya sea que nos inclinemos por uno u otro uso de los descritos anteriormente, ambos nos sugieren que estos vasitos están vinculados a prácticas que definen a esta sociedad como tal, y es por eso que las elecciones tecnológicas a la hora de manufacturarlos fueron de determinada manera y no de otra. Desde la práctica misma de hacer estos recipientes, la sociedad se está definiendo a si misma ya sea en lo referente a sus prácticas rituales o, en el caso que Doncellas estuviera inmersa dentro de una estrategia de dominio incaico, el papel preponderante que ocuparía la actividad textil dentro de esta población. En definitiva la opción tecnológica utilizada para la manufactura de estos recipientes estuvo fuertemente vinculada al sistema de representaciones de esta sociedad puneña.

Agradecimientos: Este trabajo se desarrolló gracias al financiamiento de la FFyL (UBA). Por otro lado debo agradecer el apoyo del Dr. Daniel Olivera mi director, como así también al Dr. Tchilinguirían por la realización de la interpretación petrográfica, a Mauricio Tacchia y al Ing. Scopelliti de la CONEA por la toma de las imágenes radiográficas. Por otro lado agradezco a la dirección y al personal del museo del Instituto Interdisciplinario de Tilcara Dr. Eduardo Casanova de Tilcara por el permiso otorgado para analizar la colección Doncellas allí depositada, como así también a la dirección y personal del Museo Etnográfico Juan Bautista Ambrosetti de la Ciudad Autónoma de Buenos Aires. De todos modos todas las ideas e interpretaciones del mismo son de mi exclusiva responsabilidad.

\section{Referencias bibliográficas}

Alfaro de Lanzone, Lidia

1988 Investigación en la cuenca del río Doncellas, Dpto. de Cochinoca, provincia de Jujuy. Reconstrucción de una cultura olvidada en la puna jujeña. San Salvador de Jujuy: Departamento de Antropología y Folklore, Imprenta del Estado de la Provincia de Jujuy.

ÁviLA, Florencia

2008 «Un universo de formas, colores y pinturas. Caracterización del estilo alfarero yavi de la puna nororiental de Jujuy». Intersecciones en Antropología 9: 197-212.

BenNet, Wendell C., Everett F. Bleiler y Frank Sommer

1948 Northwest Argentine Archeology. New Haven: Yale University.

BERG, Ina

2008 «Looking through Pots: Recent Advances in Ceramic X-Radiography». Journal of Archaeological Science 35: 1177-1188.

Braun, David P.

1982 «Radiographic Analysis of Temper in Ceramic Vessels: Goals and Initial Methods». Journal of Field Archaeology 9 (2): 183-192.

CARR, Christopher

1993 «Identifying Individual Vessels with Radiography». American Antiquity 58 (1): 96-117. 
Casanova, Eduardo

1938 «Investigaciones arqueológicas en Sorcuyo, Puna de Jujuy». Anales del Museo Argentino de Ciencias Naturales 39: 423-456.

1943 «Comunicación acerca del Yacimiento de Doncellas». Boletín de la Sociedad Argentina de Antropología, Resúmenes de actividades 5-6.

CRemonte, María Beatriz

1996 Investigaciones arqueológicas en la Quebrada de la Ciénaga (dto. Tafí, Tucumán). Tesis doctoral. Tucumán: Universidad Nacional de La Plata.

Cristiani Llach, Claudia M.

2009 «Evaluación de técnicas de análisis para la restauración y conservación de cerámica prehispánica». Boletín del Laboratorio de Petrología y Conservación Cerámica 2 (1).

De La Fuente, Guillermo, Norma Ratto, Gustavo Toselli y Rita Plá

2008 «Producción y tecnología cerámica: especialización y estandarización a través de la aplicación de INAA, petrología cerámica y radiografías de Rayos X en el sitio arqueológico de Batungasta, Noroeste Argentino (Abaucán, Dpto. Tinogasta, Catamarca, Argentina)», en Problemáticas de la arqueología contemporánea, Tomo II, pp. 135-144. Córdoba: Universidad Nacional de Río Cuarto.

FolK, Richard, Peter ANDrews y Daniel W. LewIS

1970 «Detrital Sedimentary Rock Classification and Nomenclature for Use in New Zealand». New Zealand Journal of Geology and Geophysics 13: 937-968.

Gatto, Santiago

1943 «Ruinas del Pucará de Humahuaca», en Congreso de historia argentina del Norte y Centro, Tomo 1, pp. 130-142. Córdoba: Editorial Litvack.

Gentile, Margarita E.

2003 «Presencia incaica en el 'paisaje de acontecimientos' de un sector de la puna de Jujuy: huanca, usnu, cachauis, y quipildor». Boletín de Arqueología PUCP 7: 217-262.

KraPOVICKAS, Pedro

1958-59«Arqueología de la Puna Argentina». Anales de Arqueología y Etnología 14-15: 53-113.

1977 «Arqueología del Cerro Colorado (Departamento Yavi, Provincia de Jujuy, República Argentina)», en Obra del centenario del Museo de La Plata. Volumen II: Antropología, pp. 123-148. La Plata: Editorial Facultad de Ciencias Naturales y Museo.

LAFON, Ciro Rene

1965 «Tiempo y cultura en la provincia de Jujuy». Etnia 2: 1-5.

LEMONNIER, Pierre

1986 «The Study of Material Culture Today: Toward an Anthropology of Technical Systems». Journal of Anthropological Archaeology 5: 147-186.

LóPEz, Mariel Alejandra

2001 «Radiografiando cerámica. Uso de la técnica médica e industrial», en Libro de resúmenes del XIV Congreso Nacional de Arqueología Argentina, p. 31. Rosario: Universidad Nacional de Rosario.

2004 «Complejidad social, especialización artesanal e innovaciones técnicas en Quebrada de Humahuaca: Un caso de cerámica Inka provincial arqueométricamente 
analizadas», en Libro de resúmenes del XV Congreso Nacional de Arqueología Argentina, p. 143. Río Cuarto: Universidad Nacional de Río Cuarto.

2008 «Alteraciones de superficie y pastas de cerámica arqueológica. Un caso de estudio en Quebrada de Humahuaca, Jujuy, República Argentina». Boletín del Laboratorio de Petrología y Conservación Cerámica 1 (2): 1-12.

LóPEz, Mariel Alejandra y Laura Valeria CARAmÉs

2000 «Restaurar para investigar. Una propuesta de conservación arqueológica». Estudios Sociales del NOA 2: 93-120.

LóPEz, Mariel Alejandra, Laura Valeria CARAmÉs y Verónica Judith ACEVEDO

2010 «El uso de rayos X en la conservación de cerámica arqueológica. Casos de estudio en Quebrada de Humahuaca, República Argentina». Ge-Conservación 1: 221-234.

Madrazo, Guillermo y María Marta Ottonello

1966 Tipos de instalación prehispánica en la región de la puna y su borde. Olavarría: Museo Etnográfico Municipal «Dámaso Arce».

Orton Clive, Paul Tyers y Alan G. VINCE

1997 La cerámica en arqueología. Barcelona: Editorial Crítica.

Otero, Clarisa

2006 «Entre muros: Tecnología cerámica en un recinto del Pucará de Tilcara (Quebrada de Humahuaca)». La Zaranda de Ideas 2: 67-85.

Ottonello de García Reinoso, María Marta

1973 «Instalación económica y cambio cultural en el sitio tardío de Agua Caliente de Rachaite». Publicaciones, Dirección de Antropología e Historia 1: 23-58.

PÉREZ, Martina Inés

2008 Nueva aproximación al estudio del material cerámico del yacimiento arqueológico del Río Doncellas (Dpto. de Cochinoca, prov. de Jujuy). Tesis de Licenciatura. Buenos Aires: Universidad de Buenos Aires.

2012 «Análisis comparativo de los conjuntos cerámicos de colecciones de museo: el caso Doncellas», en Entre pasados y presentes III. Estudios contemporáneos en ciencias antropológicas, N. Kuperszmit, T. Lagos, L. Mucciolo y M. Sacchi, comps., pp. 888-908. Buenos Aires: Editorial Mnemosyne.

PÉrez DE Micou, Cecilia

1996 Los artefactos sobre materias primas vegetales de la Colección Doncellas, Museo Etnográfico (Buenos Aires) y Museo del Pucará (Tilcara). Tesis de Doctorado. Buenos Aires: Universidad de Buenos Aires.

2001 «Cestería y cordelería para los muertos». Chungará 33 (1): 137-144.

2009 «Indicios arcaicos en la colección Doncellas, Jujuy (República argentina). El 'Yacimiento' 26 a la luz de un fechado radiocarbónico (4811+/-39 AP)». Bulletin de L'Institut Français d'Études Andines 38 (1): 75-85.

Rice, Prudence M.

1987 Pottery Analysis. A Sourcebook. Chicago: University of Chicago Press.

Rosen, Eric von

2001 Un mundo que se va. San Salvador de Jujuy: Universidad Nacional de Jujuy.

RYE, Owen S.

1981 Pottery Tecnology. Principles and Reconstruction. Washington: Taraxacum. 


\section{SHuSTER, Verónica}

2010 «Diferentes técnicas para un mismo problema: el estudio tecnológico de un conjunto cerámico fragmentario (Costa nordeste del Chubut, Patagonia Argentina)». Comechingonia Virtual 4 (1): 1-26.

Wentworth, Chester K.

1922 «A Scale of Grade and Class Terms for Clastic Sediments». Journal of Geology 30 (5): 377-392. 